\title{
ELEMENTOS DE GEOGRAPHIA E CHOROGRAPHIA DO BRASIL DE ANTONIA ANGELINA (SÉCULO XIX)
}

\author{
ELEMENTS OF GEOGRAPHY AND CHOROGRAPHY OF BRAZIL BY \\ ANGELINA ANTONIA (XIX CENTURY)
}

\author{
(iD) Vera Maria dos Santos \\ Doutora em Educação/Universidade Federal de Sergipe-UFS \\ Arac aju- Sergipe-Brasil \\ veramstos@yahoo.com.br \\ Simone Silveira Amorim \\ Doutora em Educação/Universidade Federal de Sergipe-UFS \\ Aracaju- Sergipe-Brasil \\ amorim_simone@hotmail.com \\ Ester Fraga Vilas-Bôas Carvalho do Nascimento \\ Doutora em Educação/Pontifícia Universidade de São Paulo-PUC/SP \\ Aracaju- Sergipe -Brasil \\ esterfraga@gmail.com
}

\begin{abstract}
Resumo: Este estudo tem por objetivo discutir a inserção de Antonia Angelina de Figueiredo Sá no campo intelectual da Geografia em Sergipe e, deste modo, lançar luzes sobre a constituição do campo intelectual desta disciplina, que começou a definir o seu contorno no século XIX. As fontes se constituem em livros didáticos de Geografia produzidos à época, jornais e o Dicionário biobibliográfico de Armindo Cordeiro Guaraná. Os conceitos que fundamentam esta análise são campo, de Bourdieu (1984); elites locais, de Vellasco (2004); Capital Social e Cultural, de Bourdieu (1998); e o de intelectual, de Sirinelli (1996). A análise revela a importância dessa mulher que adentrou em um campo notadamente masculino e ainda se tornou escritora de livro didático de Geografia, no século XIX, em Sergipe.
\end{abstract}

Palavras-chave: Geografia. Intelectual. Campo.

Abstract: This study aims at discussing the inclusion of Angelina Antonia de Figueiredo Sá in the intelectual field of Geography in Sergipe and thus shed light on the constitution of the intellectual field of this discipline, which began to define its outline in the nineteenth century. The sources are constituted by Geography textbooks produced at that time, newspapers and the biobibliographic dictionary by Armindo Cordeiro Guarana. The concepts underlying this analysis are field, of Bourdieu (1984), local elites, of Vellasco (2004), Social and Cultural Capital of Bourdieu (1998) and intelectual, of Sirinelli (1996). The analysis reveals the importance of this woman who entered in a particularly male field and even became a textbook writer of Geography in the nineteenth century, in Sergipe.

Keywords: Geography. Intelectual. Field.

Para citar - (ABNT NBR 6023:2018)

SANTOS, Vera Maria dos; AMORIM, Simone Silveira; NASCIMENTO, Ester Fraga Vilas -Bôas Carvalho do. Elementos de geographia e chorographia do Brasil de Antonia Angelina (século xix).

Eccos - Revista Cientifica, São Paulo, n. 54, p. 1-10, e5985, jul./set. 2020. Disponível em: https://doi.org/10.5585/eccos.n54.5985. 


\section{Introdução}

Para compor a trajetória histórica da ciência geográfica sergipana foi preciso adentrar no passado para buscar a produção intelectual de autores que escreveram sobre a Geografia sergipana. O marco temporal desta grande pesquisa foi delimitado a partir de 1800, quando foram encontradas as primeiras evidências acerca da Geografia, a 2004, ano que definimos para a finalização da coleta de dados. Nesse longo trajeto, caminhamos devagar, por caminhos ainda inacessíveis, para iluminar a História da Geografia, que antes de se estabelecer como disciplina autônoma, percorreu um longo caminho, traçado por profissionais de diversas áreas do saber.

Nessa pesquisa demonstramos, ainda, que os estudos elaborados por esses profissio na is contribuíram para o estabelecimento da Geografia em Sergipe. A partir da visualização do conjunto da produção geográfica sergipana no período mencionado, ficaram caracterizados três momentos importantes: o primeiro que, pelo predomínio das "descrições históricogeográficas", vai de 1800 a 1930; o segundo momento se caracterizou pela "delimitação do campo geográfico", que vai de 1930 a 1963; e o terceiro que, pelo "estabelecimento da autonomia do saber geográfico", vai de 1964 a 2004.

É importante enfatizar que os próprios limites desta pesquisa atestam que os estudos que compuseram este texto certamente não contemplam toda a vasta produção da geografia sergipana. Assim, este estudo diz respeito a uma das nuances deste processo, buscando compreender a constituição do campo intelectual da Geografia em Sergipe. Nesta busca nos deparamos com uma mulher, Antonia Angelina de Figueiredo Sá, em um universo predominantemente masculino. Esse fato nos chamou a atenção e decidimos investigar para saber quem foi essa mulher que se envolveu com a Geografia no século XIX, em Sergipe.

Neste artigo especificamente pretendemos lançar luzes sobre este sujeito que durante muito tempo viveu às sombras, afirmando que as mulheres, por muito tempo, não tiveram espaço para mostrar a sua face na História, muito menos na Geografia, que teve o seu campo delimitado predominantemente pelo universo masculino.

Somente nos anos setenta do século XX, sob o rótulo do movimento feminista, é que elas começaram a desencadear ações, tomar decisões políticas e se posicionar a partir do local de onde estavam falando. Com esta mudança de atitude surgiram os primeiros trabalhos sobre a atuação da mulher em seus diversos campos do saber. Mas e as mulheres de tempos remotos, por onde andam as suas histórias?

Partindo desta indagação nos propusemos a pesquisar a inserção de Antonia Angelina de Figueiredo Sá no campo intelectual da Geografia e, deste modo, discutir a respeito da 
constituição do campo intelectual dessa disciplina, que começou a definir o seu contorno no século XIX, e mostrar que a mulher esteve também presente nessa jornada no período mencionado.

As fontes que embasaram este estudo formam um corpus documental diversificado: livros didáticos de Geografia produzidos à época, jornais, Dicionário Biobibliográfico de Armindo Cordeiro Guaraná, além de uma base teórica que alicerça o estudo.

Realizamos este intento a partir da noção do conceito de campo, de Bourdieu (2004). Para o autor, o campo é um jogo no qual as regras estão, elas próprias, postas a todo o momento. O campo é um espaço de relações de forças, de convivência dos indivíduos e de disputa entre eles:

[...] a noção de campo está aí para designar esse es paço relativamente autônomo, esse microcosmo dotado de suas leis próprias. Se, como macrocosmo, ele é submetido a leis sociais, es sas não são as mesmas. Se jamais escapa as imposições do macrocos mo, ele dis põe, com relação a esta, de uma autonomia parcial. (BOURDIEU, 2004, p. 20).

Considerando que a professora Angelina só conseguiu adentrar no campo da Geografia porque pertencia à elite e que tinha capital social e cultural, é preciso entender outro conceito que é o de elites locais, de Vellasco (2004), segundo o qual são os grupos "[...] que por sua posição social, figuraram entre os grupos de maior status, poder e renda [...]" (VELLASCO, 2004, p. 213). Para Heinz (2006, p. 8), o citado conceito tem um “[...] caráter amplo e descritivo, que faz referência a categorias ou grupos que parecem ocupar o 'topo' de 'estruturas de autoridade ou de distribuição de recursos"”. De acordo com este autor, os grupos de elites são diversos:

[...] os dirigentes', 'as pessoas influentes', 'os abastados', ou os 'privilegiados', e isto, na maior parte dos casos, sem uma outra forma de justificação, uma vez que o poder da elite impor-se-ia por si próprio e prescindiria de maiores explicações. [...] As elites são definidas pela detenção de um certo poder ou então como produto de uma seleção social ou intelectual [...] (HEINZ, 2006, p. 8).

Ainda nessa análise, é significativo entender os conceitos de Capital Social e Cultural, também sob a ótica de Bourdieu. O Capital Social

[...] é o conjunto de recursos atuais ou potenciais que estão ligados à posse de uma rede durável de relações mais ou menos institucionalizadas de interconhecimento ou, em outros termos, à vinculação a um grupo, como conjunto de agentes que não somente são dotados de propriedades comuns (passíveis de serem percebidas pelo observador, pelos outros ou por eles mesmos), mas também são unidos por ligações permanentes e úteis (BOURDIEU, 1998, p. 67).

Já o Capital Cultural envolve um conjunto de bens duráveis, como afirma o próprio autor, pois: "O capital cultural pode existir sob três formas: no estado incorporado, sob a forma 
de disposições duráveis no organismo; o estado objetivado, sob a forma de bens culturais como quadros, livros, dicionários etc.; e o estado institucionalizado" (BOURDIEU, 1998, p. 72).

Ainda evocando Bourdieu (1974, p. 297), “os bens culturais enquanto bens simbólicos só podem ser apreendidos e possuídos como tais (ao lado das satisfações simbólicas que acompanham tal posse) por aqueles que detêm o código que permite decifrá-los".

Outro conceito que embasa este texto é o de intelectual, de Sirinelli (1996), que propõe duas acepções do termo considerado de caráter polissêmico da noção de intelectual, o aspecto polimorfo do meio dos intelectuais, e a imprecisão daí decorrente para se estabelecer critérios de definição do termo:

[...] uma ampla e sócio-cultural, englobando os criadores e os 'mediadores' culturais, a outra mais estreita, baseada na noção de engajamento. No primeiro caso, estão abrangidos tanto o jornalista como o escritor, o professor secundário como o erudito. Nos degraus que levam a esse primeiro conjunto posta-se uma parte dos estudantes, criadores ou 'mediadores' em potencial, e ainda outras categorias de 'receptores' da cultura (SIRINELLI, 1996, p. 242).

É sob este patamar que apresentamos a professora Antonia Angelina como objeto deste estudo, pelo fato de ela ter sido uma pessoa singular, na História do ensino da Geografia, em Sergipe. Ressalta-se que essa "[...] singularidade tinha limites bem precisos: da cultura do próprio tempo e da própria classe" (GINZBURG, 1987, p. 27).

Um tempo em que as meninas da elite sergipana recebiam a sua instrução primária não apenas nas cadeiras públicas de primeiras letras, mas também nos colégios particulares, onde eram educadas mediante os valores da sua posição social. Esta formação envolvia "[...] uma forte formação cristã, base da moral da época, à qual cabia a tarefa de modelar o caráter, mediante os preceitos e valores morais católicos" (SILVA, 2004, p. 73).

Portanto, é a partir de alguns fragmentos que mostramos o contorno da face de Antonia Angelina de Figueiredo Sá, num período em que o campo intelectual era predominantemente masculino.

\section{Antonia Angelina de Figueiredo Sá e a sua inserção no campo da Geografia}

Antonia Angelina de Figueiredo, filha do major Xavier de Figueiredo e de dona Anna Gracinda de Figueiredo, “[...] nasceu a 11 de março de 1863, no engenho Tabocal, município da Capela (SE) e faleceu em 16 de maio de 1933, em Aracaju, aos 63 anos de idade" (Cf. GUARANÁ, 1925, p. 25). Antonia Angelina foi aluna da professora Francina Telles de Menezes, da $3^{\text {a }}$ cadeira primária de Aracaju. Segundo Patrício (2003), Antonia Angelina fez o 
curso Normal, pois as professoras que ensinaram na Escola de Aprendizes e Artífices de Aracaju geralmente estudavam naquela escola.

Em Aracaju foi adjunta de professora primária da Escola de Aprendizes Artífices, em 1912. Conforme Patrício (2003, p. 168), o quadro de professores do ensino primário dessa escola era constituído pelas normalistas de formação acadêmica. O ensino envolvia: a Leitura e a Escrita, Aritmética até Regra de três, Noções de Geografia do Brasil e de Gramática Elementar da Língua Nacional.

Os professores dessa escola eram adjuntos contratados e ao final do ano eram dispensados. Se houvesse necessidade, diante do número de alunos matriculados, seriam recontratados no ano seguinte. A professora Antonia Angelina foi contratada para exercer a função acima mencionada, no ano de 1912, como mostra a nota citada por Patrício:

[...] excedendo a frequência dos cursos a 50 alumnos e a do aprendizado de alfaiataria 30, foram convocados, pelo senhor Director, em obediência ao artigo 11 do regulamento vigente, os professores d. Antonia Angelina de Figueiredo [...] para exercerem os logares de adjuntos dos professores dos cursos primários [...] (Correio de Aracaju 25/02/1912, nº 665 apud PATRÍCIO, Solange, 2003, p. 104).

No trabalho de Patrício, não encontramos nenhum outro registro acerca da professora Antonia Angelina. Supomos que ela trabalhou apenas naquele ano na Escola de Aprendizes Artífices, até mesmo porque ela fazia parte do quadro de professores "[...] effectivo do Grupo Escolar Modelo, cargo em que se jubilou em 28 de Fevereiro de 1914" (GUARANÁ, 1925, p. 14).

Para compreender a inserção dessa professora no campo intelectual não podemos deixar de nos reportar, mais uma vez, ao trabalho de Silva (2004), o qual ressaltou que "[...] a intelectualidade provincial oitocentista era composta quase que exclusivamente por homens, o que não quer dizer que não havia mulheres intelectuais ou letradas nesse período, apenas a elas não era permitido o reconhecimento" (SILVA, 2004, p. 71).

A professora jubilada, Antonia Angelina, foi uma das poucas mulheres que transgrediu as regras de inserção no campo intelectual e adentrou em um universo que era predominantemente masculino. Foi nesse universo masculino, "onde as mulheres mais 'ajudam' do que trabalham; que o seu lugar verdadeiro é o lar, que quando se aventuram para fora do lar, elas são convenientes em trabalhos que imitem as tarefas domésticas" (MALUF, 1995, p. 198), que Antonia Angelina foi de encontro “[...] à mentalidade e ao ideal predominantes que se arrastaram por quase todo o século XIX no país [onde a] 'mulher prendada' [era] praticamente impedida de ingressar no universo mais culto" (MALUF, 1995, p. 215). Bourdieu também fez uma análise a respeito da situação das mulheres que foram: 
[...] excluídas do universo das coisas sérias, dos assuntos públicos, e mais especialmente dos econômicos, as mulheres ficaram durante muito tempo confinadas ao universo doméstico e às atividades associadas à reprodução biológica e social da descendência; atividades (principalmente maternas) que, mesmo quando aparentemente reconhecidas e por vezes ritualmente celebradas, só o são realmente enquanto permanecem subordinadas às atividades de produção, as únicas que recebem uma verdadeira sanção econômica e social, e organizadas verdadeira sanção econômica e social, e organizadas em relação aos interesses materiais e simbólicos da descendência, is to é, dos homens (BOURDIEU, 1999, p. 116).

Convém ressaltar que esta condição da mulher se apresenta desde tempos remotos. Verney foi um dos intelectuais à época que se posicionou favoravelmente à educação das mulheres. Porém, enfatizo que este discurso produzido por esses intelectuais do século XVIII, sobre a educação das mulheres, não era desinteressado. Tinha um propósito, pois a sociedade portuguesa estava se adequando a um novo projeto de nação moderna e as mulheres não podiam ficar à margem dessa nova realidade. Dentro das condições estabelecidas por aqueles intelectuais, foi traçado um perfil de mulher ideal, condizente com os novos tempos, para que elas pudessem conduzir melhor o destino para o qual estavam designadas: a família e o espaço doméstico. Era essa a mulher sergipana do século XVIII e que não podia ficar à margem dessa nova realidade.

O trabalho realizado por Santos (2011) mostrou que, desde o período colonial, a mulher, apesar de ser considerada incapaz pela legislação, mais especificamente pelas Ordenações Filipinas, se impôs quando a necessidade se fez presente e desnudou a sua face e, na ausência ou falecimento do chefe da família, ela administrou os bens, os engenhos, alambiques, os sítios com suas plantações, comandou os escravos, negociou os seus produtos e fez alianças matrimoniais. Assim, a mulher se fez necessária e mostrou a sua capacidade de assumir as ocupações próprias do mundo masculino.

Para uma mulher atuar nessa sociedade havia algumas restrições. Ser homem dispensava adjetivos, pois estava inscrito no corpo um conjunto de disposições que comportava uma forma de pensar e de agir próprios:

Ser homem, no sentido de vir, implica um dever-ser, uma virtus, que se impõe sob a forma do 'é evidente por si mesma', sem discussão. Semelhante à nobreza, a honra que se inscreveu no corpo sob forma de um conjunto de disposições aparentemente naturais, muitas vezes visíveis na maneira peculiar de se manter de pé, de aprumar o corpo, de erguer a cabeça, de uma atitude, uma postura, às quais corresponde uma maneira de pensar e de agir, um éthos, uma crença etc. governa o homem de honra, independentemente de qualquer pressão externa (BOURDIEU, 1999, p. 63).

Mesmo concebendo a dissimetria entre homens e mulheres, na sociedade sergipana do citado período, a mulher exerceu muitas atividades, como a professora Angelina fez, mas 
observamos que ela não era uma mulher solteira. Ela tinha o seu anteparo social, o marido, e este fato era de grande importância.

Silva (2004) enfatizou que a legitimação dessas mulheres, ou seja, a sua inserção no meio intelectual, dava-se mediante o anteparo masculino, por meio do pai, tio, irmão ou marido. No caso da professora Antonia Angelina, a sua inserção no meio intelectual teve o anteparo do marido, o Tenente-coronel José Sotero de Sá, de quem ficou viúva aos 56 anos.

José Sotero foi agricultor, político e funcionário público. Ocupou cargos de destaque na sociedade sergipana: delegado literário, de polícia, de juiz de paz em três quatriênios na Vila de Siriri e deputado Provincial. Em Aracaju foi Tesoureiro da Tesouraria Geral da Fazenda, da Caixa Econômica, da Alfândega e administrador da Recebedoria do Estado. Esse intelectual publicou alguns trabalhos que estão citados no Dicionário Bio-bibliográfico Sergipano, de Armindo Guaraná (1925, p. 186).

O fato de o homem estar no comando de tudo estava incorporado e reproduzido pela sociedade como se fosse natural. Entretanto, para não se ter uma visão unilateral da dominação masculina, da qual a mulher seria uma vítima em potencial desse jogo, evocamos mais uma vez Bourdieu (1999) para afirmar que, no jogo da dominação, existe uma orquestração desses poderes (dominação/dominados), em que homens e mulheres estão envolvidos numa relação ou tensão de poderes e, como nos passos de uma dança, harmonizam-se - ora avançam, ora recuam.

Foi somente nas décadas de 60 e 70 do século XX, que tomou forma, no Brasil, o que em outros países já existia sob o nome de movimento feminista e, conforme afirmou Lopes,

\footnotetext{
As mulheres foram para as ruas e fizeram passeatas de protesto contra as tradicionais, e muitas vezes dissimuladas, formas de opressão; as mulheres invadiram campos profissionais até então reservados aos homens (mesmo que não se soubesse por quem) como a engenharia, a medicina, o direito; as mulheres fizeram literatura, publicaram seus diários íntimos, tornaram-se produtoras e diretoras de teatro e cinema (LOPES; GALVÃO, 2001, p. 6).
}

As autoras ressaltaram que os resultados desse movimento repercutiram nas pesquisas, mas somente no período acima mencionado que as mulheres puderam revelar as suas diversas faces sem os excessos de proibições, e sem o aparato masculino.

Retomando a análise da professora Antonia Angelina, destacamos que o fato de ela ter sido biografada por Armindo Guaraná revela a importância dessa professora no meio intelectual. Entretanto, é preciso perceber o critério de seleção do biógrafo, que tomou como base não somente o livro da professora, mas o fato de ela estar atuando no campo. Angelina foi professora pública no tempo do Império, estando, deste modo, ligada a uma instituição cultural 
- a escola - que lhe conferia o status de intelectual e ainda produziu uma obra inédita, mas que não era desconhecida no circuito intelectual sergipano da época. Mesmo assim, marcou a sua presença para além do espaço de casa, escrevendo a obra Elementos de Geographia e Chorographia do Brasil (inédito).

Até o presente momento, o livro da professora não foi encontrado, mas no Dicionário Biobliográfico de Guaraná está descrito que o livro apresentou as breves noções de Geografia Geral e demonstrou que ele obteve parecer favorável da comissão do Conselho Superior da Instrução Pública.

É importante considerar que naquele momento os manuais e os compêndios, como ressaltam muitos autores, no Brasil, eram escassos, e muitos professores de Geografia, na ausência de livros, acabavam se tornando autores e escrevendo seus livros. Assim, supomos que a citada professora produziu esse trabalho tendo em vista a escassez apontada.

O livro de Antonia Angelina revela ainda um dado importante para a história da Geografia sergipana. Pelo título da obra, Elementos de Geographia e Chorographia do Brasil, percebemos que a autora dividiu o conteúdo da Geografia em dois momentos: primeiro, Geografia Geral, e, no segundo, Geografia do Brasil. Tratou deste último num momento em que, como detectou Santos (2004), os livros de Geografia não tratavam do Brasil e sim da Geografia Geral e Cosmografia. O livro que abordou o conteúdo referente ao Brasil foi Chorographia Brasílica, de Aires de Casal, que, para muitos estudiosos, já estava defasada e não tratava a Geografia como ciência.

Diante desta constatação, acreditamos que o livro da professora Angelina foi escrito depois da publicação da Geografia Physica do Brasil Reunida, de J. E. Wappaeus, em 1884, que foi um marco na história do ensino da Geografia brasileira. Foi a partir deste que se estudou a Geografia do Brasil, pois os livros anteriores ao de Wappaeus, a exemplo das obras que circularam em Sergipe no Império, encontradas nos acervos pesquisados, tais como Lições de Geographia e Cosmographia, de L. M. Canezza, e Elementos de Geographia Moderna e Cosmographia, de autoria de P. D’ Abreu, não trataram daquele conteúdo.

\section{Conclusão}

Por intermédio do seu livro, a professora Antonia Angelina ensinou a Geografia do Brasil para os sergipanos no momento em que se reclamava a ausência de livros. A sua obra nos mostra, ainda, que a citada professora estava em concordância com as discussões travadas no campo da Geografia, em que se exigia os ensinamentos sobre o Brasil. Mas é importante 
atentar que a necessidade de se estudar o Brasil se fez presente porque houve, no início da República, uma grande preocupação com a construção nacional por meio da educação, sobretudo da educação primária.

A professora Antonia Angelina de Sá Figueiredo mostrou a sua singularidade a partir do momento que ingressou no universo masculino e ainda como forma de superar a falta de livros escreveu o seu próprio livro didático - Elementos de Geographia e Chorographia do Brasil. Deste modo, exerceu a sua profissão, que era a única permitida à mulher no século XIX, o magistério. Assim, deu a sua contribuição e se fez presente na história do ensino da Geografia em Sergipe e mostrou que a mulher esteve presente na definição do campo intelectual daquela disciplina.

Pesquisas dessa natureza mostram que as mulheres assumiram ocupações que, como visto, estavam além das atividades domésticas. O registro de tais ocupações desmistifica o ideal composto pela historiografia sergipana e brasileira de que a mulher na história viveu submissa, reclusa e sem trabahar. Afirmamos, ainda, que somente é possível mostrar a verdadeira face da mulher sergipana e brasileira buscando os poucos registros que guardam os indícios de práticas da vida das mulheres, os quais permitem rever a história do cotidiano feminino em épocas remotas.

Vimos que a constituição do campo intelectual da Geografia não era predominanteme nte masculina. A inserção de Antonia Angelina de Figueiredo Sá nesse campo foi importante para percebermos que o contorno do campo intelectual dessa disciplina vem revelando, ao longo desta pesquisa, as suas especificidades como esta, que mostra que a mulher esteve também presente nessa jornada no período mencionado. Até o presente momento foi a primeira mulher encontrada no século XIX como escritora de livro didático e professora. 


\section{Referências}

BOURDIEU, Pierre. Os usos sociais da ciência: por uma Sociologia clínica do campo científico. São Paulo: UNESP, 2004.

BOURDIEU, Pierre. A economia das trocas simbólicas. Introdução, organização e seleção Sérgio Miceli. São Paulo: Perspectiva, 1974.

BOURDIEU, Pierre. A dominação masculina. Trad. Maria Helena Kühner. Rio de Janeiro: Bertrand Brasil, 1999.

BOURDIEU, Pierre. Escritos de Educação. Petrópolis, Vozes, 1998.

FERNANDES, Manoel. Reflexões sobre a investigação em História da formação de professores de Geografia. In: PONTUSCHKA, Nídia Nacib; OLIVEIRA, Ariovaldo Umbelino de (org.). Geografia em perspectiva. São Paulo: Contexto, 2002.

GINZBURG, Carlo. O queijo e os vermes: o cotidiano e as idéias de um moleiro perseguido pela Inquisição. São Paulo: Companhia das Letras, 1987.

GUARANÁ, Manoel Armindo Cordeiro. Dicionário Bio-Bibliográfico Sergipano. Rio de Janeiro: Governo do Estado de Sergipe: Pongetti, 1925.

LOPES, Eliane Marta Teixeira; GALVÃO, Ana Maria de Oliveira. História da educação. Rio de DP\&A, 2001.

MALUF, Marina. Ruídos da memória. São Paulo: Siciliano, 1995.

PATRÍCIO, Solange. Educando para o Trabalho: Escola de Aprendizes e Artífices em Sergipe (1911-1930). 2003. Dissertação (Mestrado em Educação) - Núcleo de Pós-Graduação em Educação, Universidade Federal de Sergipe, Aracaju, 2003.

PINA, Maria Lígia Madureira. A mulher na História. s/ed. s/d.

SANTOS, Vera Maria dos. A Geografia e os seus livros didáticos sobre Sergipe, do século XIX ao século XX. Aracaju: Editora do Diário Oficial de Sergipe- Edise, 2017.

SANTOS, Vera Maria dos. As mulheres de posses: a instrução dos órfãos menores na Capitania de Sergipe Del Rey no século XVIII. Fortaleza: Imprece, 2016.

SILVA, Eugenia Andrade Vieira. A formação intelectual da elite sergipana (1822-1889). 2004. Dissertação (Mestrado em Educação) - Núcleo de Pós-Graduação em Educação, Universidade Federal de Sergipe, São Cristóvão, 2004.

SIRINELLI, Jean-François. “Os intelectuais". In: RÉMOND, René. (org.). Por uma história política. Rio de Janeiro: Editora UFRJ. Fundação Getúlio Vargas, 1996. p. 231-263. 